\title{
Synthesis and Supramolecular Association of Immobilized NCN-Pincer Platinum(II) Complexes on Hyperbranched Polyglycerol Supports
}

\author{
Salah-Eddine Stiriba, ${ }^{*[a, d]}$ Martijn Q. Slagt ${ }^{[b]}$ Holger Kautz ${ }^{[c]}$ \\ Robertus J. M. Klein Gebbink, ${ }^{[\mathrm{b}]}$ Ralf Thomann, ${ }^{[\mathrm{c}]}$ Holger Frey, ${ }^{*[\mathrm{~d}]}$ and \\ Gerard van Koten ${ }^{*[b]}$
}

\begin{abstract}
Pertosylation of hyper-
branched polyglycerol $\quad\left(M_{\mathrm{n}}=2000\right.$;

$M_{\mathrm{w}} / M_{\mathrm{n}}=1.3$ ) followed by partial displacement of the tosyl groups with carboxylic acid functionalized NCN-pincer platinum(II) complexes [PtI-2,6$\left.\left(\mathrm{NMe}_{2} \mathrm{CH}_{2}\right)_{2} \mathrm{C}_{6} \mathrm{H}_{2}-4-\mathrm{COOH}\right]$, resulted in covalent attachment of the NCNpincer complexes to the polyglycerol. These functionalized hyperbranched macromolecules have been character-
\end{abstract}

ized by ${ }^{1} \mathrm{H},{ }^{13} \mathrm{C}$, and ${ }^{195} \mathrm{Pt} \mathrm{NMR}$, UVvisible, and IR spectroscopy. The presence of $\mathrm{Pt}$ and $\mathrm{I}$ atoms renders them

$\begin{array}{lr}\text { Keywords: } & \text { aggregation } \\ \text { hyperbranched } & \text { polymer } \\ \text { immobilization } & \cdot \\ \text { complexes } & \text { platinum } \\ \text { chemistry } \cdot \text { transmission electron } \\ \text { microscopy }\end{array}$

directly visible by transmission electron microscopy (TEM) without staining procedures, which offers images of associated hyperbranched macromolecules. TEM micrographs show diskshaped structures with a small size-distribution (15-20 nm), and characteristic core-shell ring structures. The thickness of the corona observed in TEM could be correlated with the substitution degree with pincer platinum moieties.

\section{Introduction}

Immobilization of functional molecules on dendritic scaffolds in either a covalent or non-covalent fashion, and the control of their supramolecular architectures have been a subject of intense research in the last decade. ${ }^{[1]}$ This is important to tailor the properties of the supramolecular mate-

[a] Dr. S.-E. Stiriba

Instituto de Ciencia Molecular/Facultad de Farmacia

Av. Vicent Andrés Estelles, s/n

46100 BurjassotValencia (Spain)

Fax: (+34) 96-354-4939

E-mail: salah.stiriba@uv.es

[b] Dr. M. Q. Slagt, Dr. R. J. M. Klein Gebbink, Prof. Dr. G. van Koten Debye Institute, Department of Metal-Mediated Synthesis Utrecht University, Padualaan 8

$3584 \mathrm{CH}$ Utrecht (The Netherlands)

Fax: $(+31) 30-252-3615$

E-mail: g.vankoten@chem.uu.nl

[c] Dr. H. Kautz, Dr. R. Thomann

Institut für Makromolekulare Chemie und Freiburger

Materialforschungszentrum FMF Albert-Ludwigs-Universität

Freiburg, Stefan-Meier Str. 21/31

79104 Freiburg (Germany)

[d] Dr. S.-E. Stiriba, Prof. Dr. H. Frey

Institut für Organische Chemie, Johannes Gutenberg

Universität, Duesbergweg 10-14, 55099 Mainz (Germany)

Fax: (+49)6131-39 26106

E-mail: salah.stiriba@uv.es

hfrey@mail.uni-mainz.de rial. Supramolecular association based on dendritic architecture can be useful to provide nanoscale dimensions. The investigation and elucidation of the shape of dendritic building blocks in both solution and in bulk is a crucial prerequisite to control their design, and to then fine-tune their properties. In this context, the application of transitionmetal complexes in dendrimer chemistry as building blocks or functional moieties has attracted specific interest. ${ }^{[2]}$ Both dendrimers and hyperbranched polymers functionalized with catalytically active transition-metal complexes are promising scaffolds with respect to catalyst recovery. ${ }^{[3]}$ To this end, it is essential to analyse the possible macro-architecture that results from aggregation of the dendritic blocks bearing transition-metal complexes. In addition, dendrimers and hyperbranched macromolecules are interesting for the design of new materials with intriguing optical or electrochemical properties, and for diagnostic applications in medicine ${ }^{[4]}$ Since dendrimers have to be prepared in tedious multistep syntheses, which is a limiting parameter for most (large scale) applications, hyperbranched polymers offer a promising alternative. ${ }^{[5]}$ These hyperbranched polymers are obtained in one-pot syntheses from branched $\mathrm{AB}_{m}$-type monomers, which results in a randomly branched globular polymeric structure with a broad molecular-weight distribution. ${ }^{[5-\mathrm{e}]}$ Important recent progress in this field has been made with the development of slow monomer-addition strategies, which results in pseudo chain-growth and thus controlled molecular weights of the polymers, which is deter- 
mined by the monomer to initiator ratio. In this regard, anionic ring-opening multibranching polymerization (ROMBP) of glycidol results in a well-defined hyperbranched polyglycerol, which can be tailored in terms of core functionality and molecular weight. ${ }^{[6]}$ The narrow polydispersity of these materials $\left(1.3<M_{\mathrm{w}} / M_{\mathrm{n}}<1.5\right)$, and the flexibility of the chemically inert polyether structure, allows further specific functionalization. ${ }^{[7]}$ To date, there are only few reports on the attachment of catalytically active transition-metal complexes to hyperbranched polymers. ${ }^{[1 \mathrm{c}]}$ In previous work, an approach to hyperbranched polycarbosilanes functionalized with aryldiamine palladium(II) complexes has been established by our group. ${ }^{[8]}$ The soluble macromolecular multisite catalyst obtained was as catalytically active as its carbosilane dendrimer analogue, and was suitable for continuous membrane applications.

Apart from being catalytically active compounds or sensor materials, organometallic NCN-pincer complexes (NCN-pincer $=2,6$-bis [(dimethylamino)methyl $]$ phenyl

anion) are attractive building blocks, since they can be prepared with various para-substituents as anchoring moieties for immobilization purposes. ${ }^{[9,10]}$ Covalent introduction of these transition-metal complexes is also of interest in view of visualization and imaging of dendritic polymers by transmission electron microscopy (TEM). The electron-rich metal ions in the polymer structure create enhanced contrast and should permit direct visualization of isolated polymer molecules or supramolecular structures. $^{[11]}$

To date, only few molecular images of dendritic macromolecules have been published, because their size range $(2-10 \mathrm{~nm}$ for dendrimers) and noncontrasting organic composition renders resolution by TEM to be very difficult. Moreover, the application of staining techniques to such small structures is not trivial. ${ }^{[12]}$ Here, we report a synthetic approach, in two steps for NCN-pincer platinum(II)substituted polyglycerols obtained by nucleophilic displacement of a tosylated polyglycerol by the potassium carboxylate of a platinated NCN-pincer precursor, in order to prepare platinated hyperbranched catalysts. The platinated hyperbranched polyglycerols have been directly visualized by TEM, and compared to shapepersistent multi NCN-pincer platinum complexes with respect to size and structure.

\section{Results}

Synthesis: Tosylation of the hydroxyl groups of $\mathrm{PG}_{25}$ (1) $\left(M_{\mathrm{n}}=2000 ; M_{\mathrm{w}} / M_{\mathrm{n}}=1.3\right)$ was carried out by using two equivalents of para-tosyl chloride for each hydroxyl group at $80^{\circ} \mathrm{C}$, which resulted in the pertosylated polyglycerol $\mathrm{P}\left(\mathrm{G}_{25} \operatorname{Tos}_{1}\right)$ (2) (Scheme 1). ${ }^{[13]}$ This compound was further purified by dialysis in chloroform. The purity and molecular weight were confirmed by ${ }^{1} \mathrm{H}$ and ${ }^{13} \mathrm{C}\left\{{ }^{1} \mathrm{H}\right\} \mathrm{NMR}$, IR, UVvisible spectroscopy, and elemental analysis. The tosylated material was completely and homogenously soluble in apolar solvents, in contrast to the hydrophilic starting material.

Grafting of the NCN-pincer platinum(II) complexes was achieved by nucleophilic displacement of the tosylate groups by carboxylated NCN-platinum(II) complexes. The platinated NCN-pincer carboxylic acid $(4)^{[10]}$ was deprotonated for this purpose by treatment with potassium tert-butoxide $(t \mathrm{BuOK})$ in THF. The potassium carboxylate $\mathbf{5}$ immediately precipitated from the solution (Scheme 2). Based on the number of tosylate groups per polyglycerol, which is approximately equal to its $\mathrm{DP}_{n}$ (degree of polymerization) $(n=25)$, we treated 2 with an excess of 5 in DMF at $80^{\circ} \mathrm{C}$ (Scheme 1).

Irrespective of the excess of 5 (10-100\%) employed in the substitution reactions, only $50 \%$ of the available tosylate

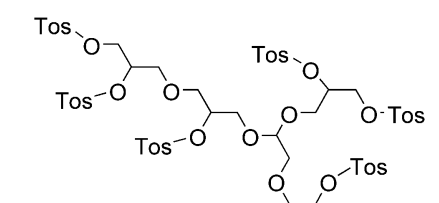

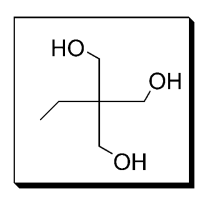
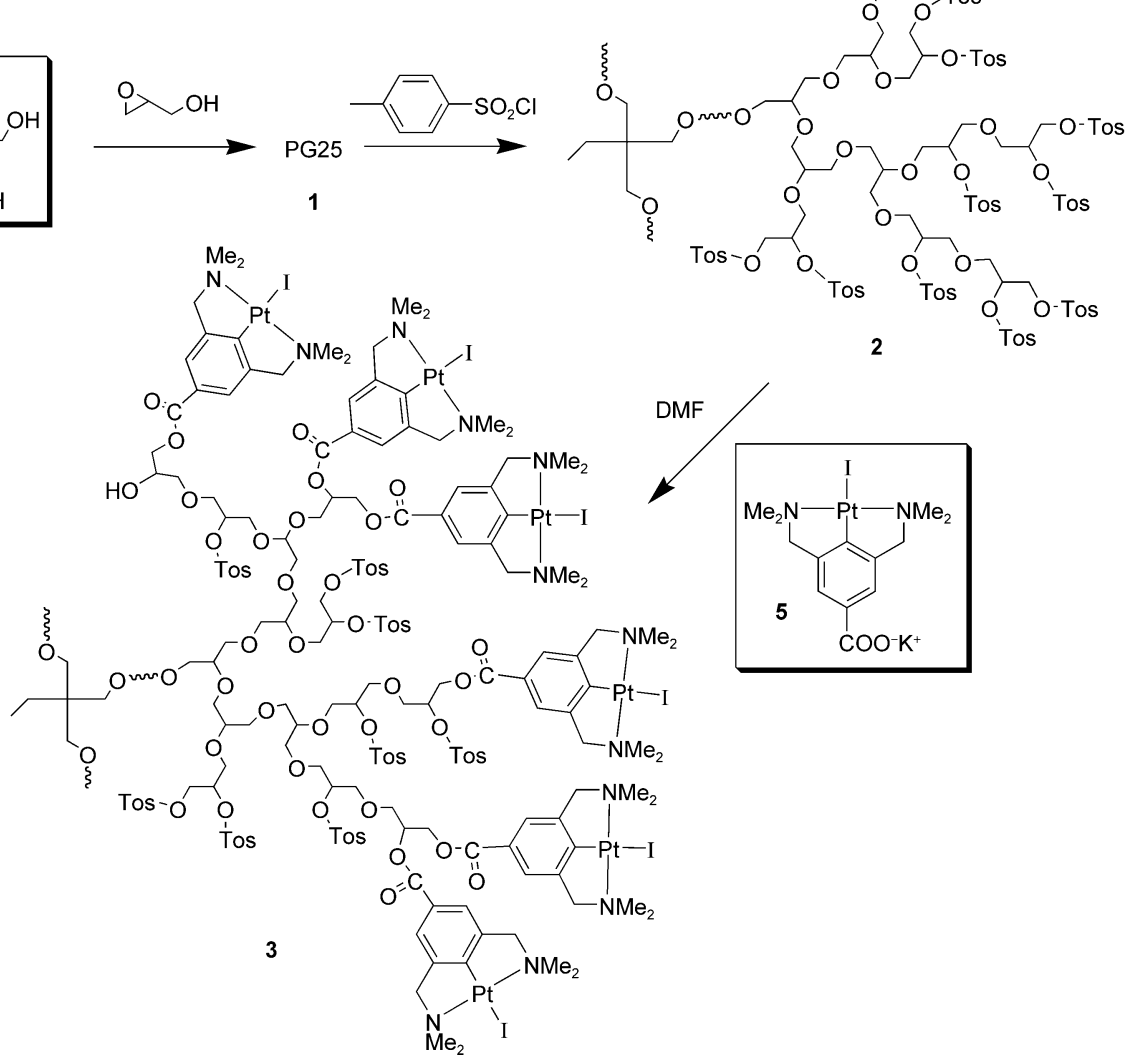

Scheme 1. Synthesis of the pertosylated hyperbranched polyglycerol $\mathbf{2}$ followed by partial substitution of tosyl groups with NCN-pincer platinum(II) carboxylates to afford $\mathbf{3}$. 
<smiles>CN1Cc2cc(C(=O)O)cc(c2P)C1(I)I</smiles>

4

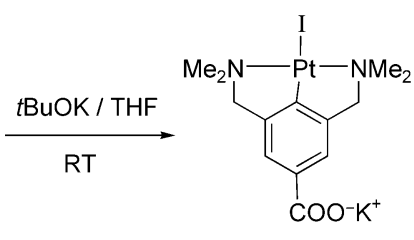

5
Scheme 2. Synthesis of the potassium carboxylate NCN-pincer platinum complex 5.

groups could be replaced by the organometallic carboxylate, which afforded the modified hyperbranched polymer $\mathbf{3}$ (Scheme 1). Organometallic polymer $\mathbf{3}$ is constructed from 25 monomer units, with $50 \%$ of its hydroxyl groups substituted by NCN-pincer platinum iodide units, and 50\% remaining tosyl groups. Thus, each modified polyglycerol molecule contains on average 12.5 platinum sites and 12.5 tosylate groups. Unreacted compound $\mathbf{5}$ was removed from $\mathbf{3}$ by repeated liquid-liquid extractions with water, and subsequent dialysis, MWCO (molecular weight cut off) $=1000 \mathrm{D}$, by using chloroform. Finally, separation by preparative SEC (size exclusion chromatography) equipped with a UV-visible detector was performed in order to study the fractions of different molecular weight with respect to their degree of NCNpincer platinum substitution, and supramolecular-structure formation. The corresponding SEC diagram with the fractions sampled is shown in Figure 1. Apparently, both aqueous extractions, and dialysis of the crude coupling product were not sufficient enough to completely remove unreacted $\mathbf{5}$.

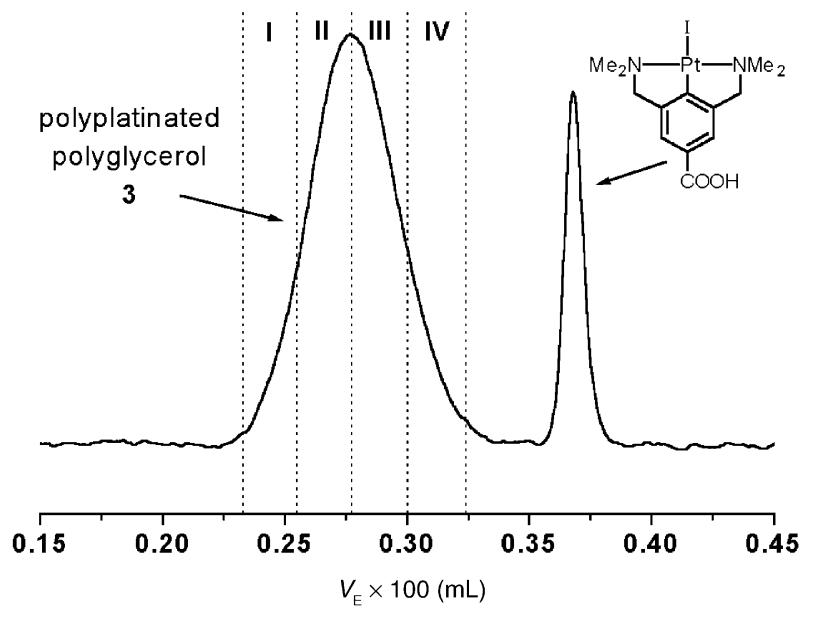

Figure 1. Preparative SEC traces of the separation and fractionation of $\mathbf{3}$.
The immobilized platinum (II) iodide complexes could be converted in their cationic aqua complexes by dehalogenation upon treatment with $\mathrm{AgBF}_{4}$. The activity of dehalogenated $\mathbf{3}^{[14]}$ in the double Michael addition of two equivalents of methyl vinylketone to ethyl cyanoacetate as a model reaction has been tested. The observed reaction-rate for macromolecule $3\left(191 \times 10^{-3} \mathrm{~h}^{-1}\right)$ was relative to that of a nonimmobilized pincer-complex $\left[\mathrm{Pt}\left(\mathrm{OH}_{2}\right) \mathrm{NCN}\right]^{+} \mathrm{BF}_{4}^{-} \quad(280 \times$ $\left.10^{-3} \mathrm{~h}^{-1}\right)$. Separation of products and catalyst $\mathbf{3}$ after full conversion was achieved conveniently by dialysis against neat dichloromethane. The catalytic material $(7.3 \mathrm{mg}$, $0.65 \mu \mathrm{mol})$ was recovered in near quantitative yields $(92 \%)$.

TEM characterization: TEM images of the platinum(II), that contained macromolecule 5 were obtained by depositing a dilute solution on carbon-coated electron microscopy grids, followed by evaporation of the solvent. The presence of the platinum and iodine atoms in the hyperbranched materials renders them directly visible by TEM, and leads to the possibility to study their aggregation behavior and supramolecular structures in more detail. Figure 2 represents the TEM
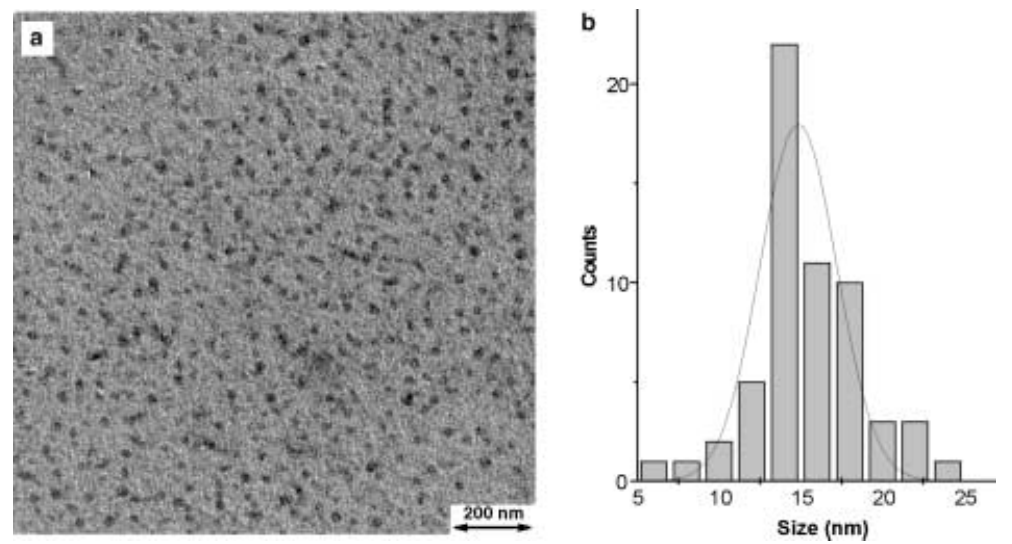

Figure 2. a) TEM image of $\mathbf{3}$ before SEC fractionation and b) histogram of the particle size distribution.

image obtained for a sample of $\mathbf{5}$ prior to fractionation, and shows the presence of particles in the size range of 10 $25 \mathrm{~nm}$.

In order to obtain a more detailed insight, fractions obtained from preparative SEC were employed in the TEM studies. ${ }^{[15]}$ Figure $3 a$ and $b$ show the noncontrasted images of two typical fractions (fraction II and fraction IV) of the Ptloaded hyperbranched polymers. For these, and all other samples studied, a remarkable narrow size distribution of the nanostructures was observed.

For comparison we also studied the earlier reported ${ }^{[16]}$ rigid dodeca-platinated NCN-pincer complex $\mathbf{6}$ as depicted. This complex has a calculated diameter of $3.2 \mathrm{~nm}$ (from MM2 calculations) and is a monodisperse compound, in contrast to the hyperbranched polymers that possess quite narrow, yet non-negligible molecular-weight distributions. A TEM-image of $\mathbf{6}$, together with the corresponding histogram is shown in Figure 4. 

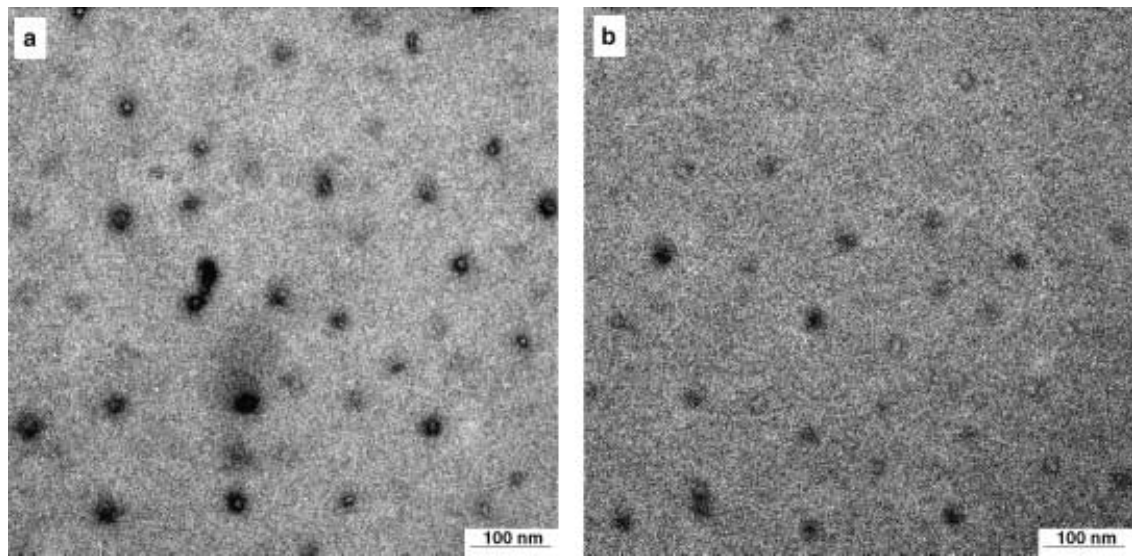

preparation of an activated polyglycerol derivative with easily displaceable tosyl groups. Full tosylation was confirmed both by NMR spectroscopy, and the disappearance of the OH-band in the IR spectra. Surprisingly, substitution of the tosylate groups on $\mathbf{2}$ with $\mathbf{5}$ did not result in the formation of a fully platinated polyglycerol polymer. No evidence was found for preferential substitution of either primary or secondary tosylate groups of the tosylated hyperbranched polyglycerols. We tentatively explain the incomplete substitution by excessive steric crowding of the bulky pincer system, separation.
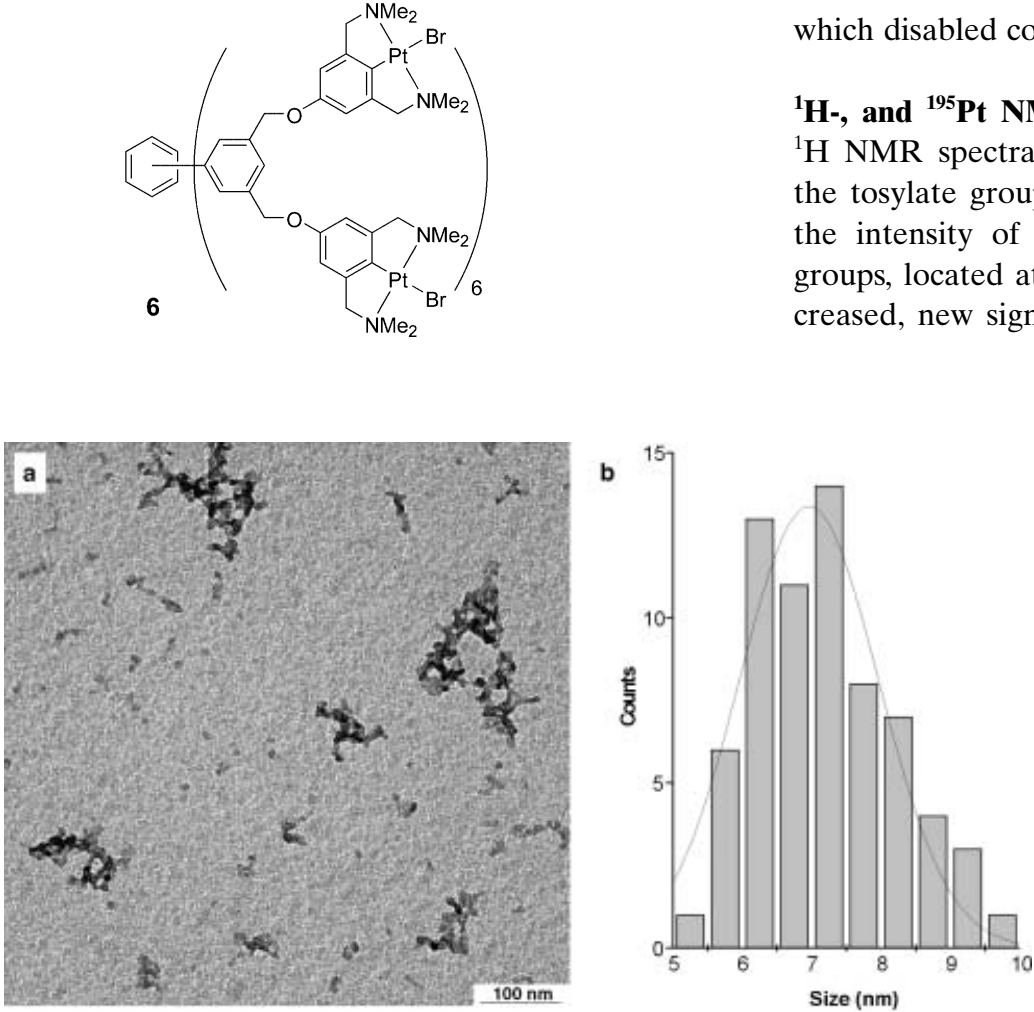

Figure 4. a) TEM image of the dodecaplatinum(II) pincer 6 and b) histogram of particle size distribution.

which disabled complete substitution.

${ }^{1} \mathrm{H}$-, and ${ }^{195} \mathrm{Pt}$ NMR spectroscopy, and UV-visible analysis: ${ }^{1} \mathrm{H}$ NMR spectra of $\mathbf{3}$ clearly show partial replacement of the tosylate groups by $\mathrm{NCN}$-pincer platinum groups. While the intensity of the signals originating from the tosylate groups, located at 7.78, $7.36(\mathrm{ArH})$ and $2.45 \mathrm{ppm}\left(\mathrm{CH}_{3}\right)$ decreased, new signals appeared at $7.56(\mathrm{ArH}), 4.07\left(\mathrm{CH}_{2} \mathrm{~N}\right)$, and $3.19 \mathrm{ppm}\left(\mathrm{NMe}_{2}\right)$, which is typical of platinated NCNpincer complexes. The degree of substitution was determined to be $50 \%$ by the relative intensity ratios of these signals. The ${ }^{3} J_{\mathrm{Pt}-\mathrm{H}}$ couplings of $\mathbf{4}$ with the $\mathrm{NMe}_{2}(28.8 \mathrm{~Hz})$ and $\mathrm{CH}_{2} \mathrm{~N}$ $(39.0 \mathrm{~Hz})$ protons in the ${ }^{1} \mathrm{H}$ NMR spectra were not fully resolved in spectra of $\mathbf{3}$, due to broadening of the signals caused by the immobilization on a polymeric support. ${ }^{195} \mathrm{Pt}$ NMR spectroscopy clearly showed the presence of one discrete platinum(II) site, which originated from the immobilized NCN-pincer complexes as a single resonance at

\section{Discussion}

Synthesis: Hyperbranched polyglycerols possess terminal and internal hydroxyl groups, which can be functionalized through several routes. ${ }^{[7]}$ Esterification with acyl chlorides in a mixture of pyridine/toluene affords partially esterified polyglycerols that have been demonstrated to form compact "nanocapsule" structures in apolar media. ${ }^{[7, e, 1 \mathrm{~h}]}$ This direct substitution route turned out to be impractical for the introduction of the pincer complexes, since the corresponding acyl chloride of $\mathbf{4}$ was prepared in low yields, and had to be reacted with polyglycerol under harsh reaction conditions. We therefore turned to an alternative strategy, that is, the
-1914 ppm. For comparison, carboxylic acid 4 showed a singlet located at $-1899 \mathrm{ppm}$ in the ${ }^{195} \mathrm{Pt}$ NMR spectrum. UVvisible spectroscopic analysis of tosylated polyglycerol $\mathbf{2}$ in chloroform showed an absorption band at $262 \mathrm{~nm}(\varepsilon \approx$ $10^{5} \mathrm{M}^{-1}$ ). In the spectra (UV/Vis) of $\mathbf{3}$ an additional band shows up at $324 \mathrm{~nm}\left(\varepsilon \approx 10^{5} \mathrm{M}^{-1}\right)$, which originates from the NCN-pincer platinum moieties covalently linked to the polymer. For comparison, the NCN-pincer platinum carboxylate 4 exhibits an absorption band located at $326 \mathrm{~nm}(\varepsilon \approx$ $10^{4} \mathrm{M}^{-1}$ ). Furthermore, in the spectra (UV/Vis) of 2 and the polyplatinated polymer $\mathbf{3}$, the shoulder of an additional absorption band with its maximum located below $225 \mathrm{~nm}$ was visible. 
TEM characterization: In contrast to dendrimers, molecular images of hyperbranched macromolecules have not yet been reported. The introduction of heavy atoms ( $\mathrm{Pt}, \mathrm{I}$ ) on the polyglycerol backbone permits imaging of molecular or defined supramolecular structures of the materials by TEM without staining procedures. The platinum(II) atoms are covalently bonded to the aryl carbon atom in the stabilizing coordination environment of the NCN-pincer ligand. This in turn is covalently linked to the polyglycerol structure, thereby ensuring that the metal is attached to the hyperbranched polyglycerol support and cannot leach from the material without cleavage of the ester bond.

In the TEM image of 3 (Figure 2), prior to fractionation by SEC, the functionalized hyperbranched polymers appear as dark spots in the range of $10-25 \mathrm{~nm}$. Since the size of single hyperbranched macromolecules is expected to be in the range of $5-10 \mathrm{~nm}$ based on the molecular modeling of their three dimensional structures, by considering surface interaction and consequent flattening of the structures, these metal-rich particles are due to the association of the macromolecules, not unimolecular species. SEC revealed that the sample still contained unreacted $\mathbf{5}$, which is expected to be accommodated in the polyglycerol core of the hyperbranched polymeric aggregates, which resulted in the observed problems when attempting to remove this material by dialysis, and repeated washing with aqueous solution. The TEM-images of the SEC fractions II and IV (Figure 3a and $b$ ) show particles of rather narrow polydispersity. In many cases, an unusual core-shell-type substructure with lighter cores and darker corona is observed. In view of the smaller size of single hyperbranched macromolecules, we interpret the core-shell structures as collapsed micellar aggregates of the functionalized hyperbranched polymers. The observed core-shell separated structure can be attributed to differences in polarity between the polyglycerol backbone and the NCN-pincer platinum(II) moieties mainly located in the periphery. In the less contrasting core of the structures only the polyether scaffold is present, while in the dark corona of the core-shell assemblies the NCN-pincer platinum(II) complexes dominate. An intuitive two-dimensional projection that can account for the observed core-shell-separated structure is given in Scheme 3.

An additional feature shown in Figure $3 a$ and $b$ is an increase in the size of the dark corona for the higher molecular-weight fractions. The TEM image of fraction II (Figure 3a) shows dense coronas, while for the lower molecular- weight fraction IV (Figure 3b) less contrasted coronas are observed. The molecular weight of the functionalized polyglycerol (molecular weight of $\mathbf{2}$ amounts to $5800 \mathrm{D}$ ) is highly dependent on the substitution degree with relatively heavy NCN-pincer complexes (molecular weight of $\mathbf{5}$ equals 557.3). The thickness of the corona can thus be correlated with the degree of polyglycerol substitution. With an increase in the degree of substitution, the size of the NCNpincer platinum(II) rich corona increases. We tentatively conclude that the unusual aggregation of $\mathbf{3}$ is a consequence of the flexible polar structural core of the hyperbranched polyglycerols. In order to rationalize the behavior of NCNpincer platinum species in TEM studies, a previously described NCN-pincer Pt-loaded dendrimer loaded scaffold 6 was also investigated. The TEM image of 6 (Figure 4a) shows this dodeca-platinated NCN-pincer species as roughly spherical dark spots, which in certain cases assemble to irregularshaped aggregates. This irregular aggregation is most likely to be attributed to the TEM sample preparation. The particle size of the individual black dots, as can be deduced from the histogram (Figure $4 \mathrm{~b}$ ), is in the range of 5-10 nm. As shown in Figure 4, no core-shell-type supramolecular organization similar to $\mathbf{3}$ is observed. Both TEM studies clearly show that the attached NCN-pincer platinum species can be applied conveniently for the imaging of small (dendritic) molecules and their supramolecular structures by TEM, without the need for staining procedures. The broad range of available para-substituted NCN-pincer complexes ${ }^{[10]}$ makes their (covalent) attachment to virtually any (organic) scaffold feasible, which allows electron microscopic studies to be performed.

\section{Conclusion}

The activation of hyperbranched polyglycerols through tosylation was found to be an efficient method to produce suitable starting materials for further functionalization. The nucleophilic displacement of the tosyl groups by NCN-pincer platinum(II) carboxylate (5) gives access to a new polyorganometallic polyglycerol polymer $\mathbf{3}$ with discrete platinum(II) sites. The presence of the covalently bound heavy platinum and iodine atoms in this polyorganometallic material, allowed visualization of organized supramolecular structures by TEM without the need to use staining techniques; which shows core-shell type aggregates. To the best of our knowl-

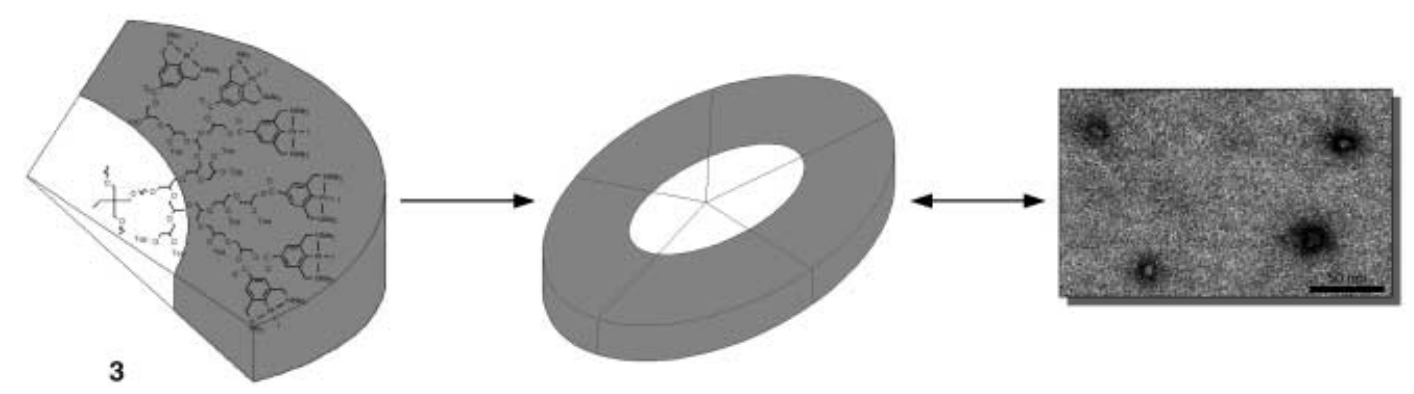

Scheme 3. Two-dimensional projection model for the core-shell micelle structure of aggregation for 3. 
edge, this is the first time that transition-metal complexes have been linked to a hyperbranched polyether backbone, and TEM has been applied to study the size and shape of such species.

\section{Experimental Section}

All reactions were performed under an inert argon atmosphere. Polyglycerol $1\left(\mathrm{DP}_{n}=25, M_{\mathrm{n}}=2000, M_{\mathrm{n}} / M_{\mathrm{w}}=1.3\right)$ was prepared as reported previously, ${ }^{[6]}$ by using trimethylolpropane (TMP) as an initiator. NCNpincer platinum complex $\mathbf{4}^{[10]}$ and the dodecaplatinum(II) pincer dendrimer $\mathbf{6}^{[16]}$ were prepared according to literature procedures. Pyridine was distilled from $\mathrm{KOH}$, toluene, and DMF was distilled from calcium hydride; all other solvents were used without further purification. $p$-Tosyl chloride and tert-butoxide potassium were purchased from Aldrich. Benzoylated cellulose tubing for dialysis $(\mathrm{MWCO}=1000 \mathrm{D})$ was obtained from Sigma.

${ }^{1} \mathrm{H}$ NMR and ${ }^{13} \mathrm{C}\left\{{ }^{1} \mathrm{H}\right\}$ NMR spectra were obtained from solutions in $\mathrm{CDCl}_{3}$ on a Bruker ARX 300 spectrometer operating at 300 and 75.4 MHz, respectively. ${ }^{159} \mathrm{Pt}\left\{{ }^{1} \mathrm{H}\right\}$ NMR spectra were measured by using a Varian Inova 300 from solutions in $\mathrm{CDCl}_{3}$. IR spectra were recorded on a Bruker Vector 22 spectrophotometer, by using thin polymer films on $\mathrm{KBr}$ disks. UV/Vis spectra were obtained by using a Perkin-Elmer Lambda 2 spectrophotometer. Preparative GPC (gel permeation chromatography) was carried out on an MZ-Gel Sdplus column $(250 \times 40 \mathrm{~mm})$ by means of THF (p.a.) as eluent. The separation of the samples was monitored by using a variable wavelength monitor at $320 \mathrm{~nm}$ with a flow of $5 \mathrm{~mL} \mathrm{~min}^{-1}$

TEM measurements: TEM analyses were carried out on a LEO 912 Omega apparatus by using an acceleration voltage of $120 \mathrm{kV}$. Samples were prepared by applying a drop of the THF solvated organometallic macromolecule $\mathbf{3}$ to a carbon-coated grid, followed by drying the sample in air. Samples were generally not stained.

Tosylated polyglycerol 2: $p$-Toluene sulfonic acid chloride $(25.7 \mathrm{~g}$, $135 \mathrm{mmol})$ in pyridine $(150 \mathrm{~mL})$ at $50^{\circ} \mathrm{C}$ was added dropwise to a solution of dried hyperbranched polyglycerol $\left(\mathrm{DP}_{n}=25\right) \mathbf{1}(5 \mathrm{~g}, 67.5 \mathrm{mmol}$ of $\mathrm{OH}$ groups) in pyridine $(100 \mathrm{~mL})$. The resulting mixture was stirred at $80^{\circ} \mathrm{C}$ for $3 \mathrm{~h}$. After cooling to room temperature chloroform $(200 \mathrm{~mL})$ was added, and the solution was poured onto a mixture of ice and $\mathrm{HCl}$ solution $(100 \mathrm{~mL}$ of $10 \mathrm{~N})$. The organic layer was separated, washed three times with water, and dried over $\mathrm{Na}_{2} \mathrm{SO}_{4}$. The product was transferred to benzoylated cellulose tubing for dialysis in chloroform overnight. Chloroform was removed under vacuum pressure, and the product was dried under vacuum, yielding a yellowish oil $(70 \%)$. ${ }^{1} \mathrm{H}$ NMR $(300 \mathrm{MHz}$, $\left.\mathrm{CDCl}_{3}\right): \delta=1.19\left(\mathrm{t}, 3 \mathrm{H} ; \mathrm{CH}_{3}\right.$, initiator TMP), 2.32 (s, $3 \mathrm{H} ; \mathrm{CH}_{3}$, tosylate), 2.34 (s, 3H; $\mathrm{CH}_{3}$, tosylate), 3.37-3.95 (m, br, polyether scaffold), 3.974.04 (q, $2 \mathrm{H} ; \mathrm{CH}_{2}$, initiator TEM), 4.45-4.58 (br m, polyether scaffold), 7.23-7.26 (m, 4H; tosylate), 7.64-7.70 ppm (m, 4H, tosylate); ${ }^{13} \mathrm{C}\left\{{ }^{1} \mathrm{H}\right\}$ NMR (75.4 MHz, $\left.\mathrm{CDCl}_{3}\right): \delta=14.5\left(\mathrm{CH}_{3}, \mathrm{TEM}\right), 21.5\left(\mathrm{CH}_{3}\right.$, tosylate), 66.7, 67.1, 67.26, 68.0, 68.7, 69.7, 71.4, 77.2, 77.4, 127.6, 128.5, 129.8, 132.0, $132.5,132.8,132.9,133.1,133.6,139.2,143.4,144.5,144.8,145.1 \mathrm{ppm}$; IR $(\mathrm{KBr}): v=1595(\mathrm{C}-\mathrm{H}$ aromatic), $1494(\mathrm{C}-\mathrm{H}$ aromatic), $1453(\mathrm{C}-\mathrm{H}$ sat $)$, $1420-1330(\mathrm{~S}=\mathrm{O}), 1200-1145(\mathrm{~S}=\mathrm{O}), 1170 \mathrm{~cm}^{-1}(\mathrm{C}-\mathrm{O})$. UV/Vis $\left(\mathrm{CHCl}_{3}\right)$ : $\lambda_{\max }(\varepsilon)=334 \mathrm{~nm}$; elemental analysis calcd (\%) C 52.38, H 5.71, S 13.98; found: C 52.33, H 5.15, S 12.85 .

Synthesis of pincer complex 5: A stoichiometric amount of $\mathrm{KO} t \mathrm{Bu}$ $(0.10 \mathrm{~g}, 0.90 \mathrm{mmol})$ in THF $(20 \mathrm{~mL})$ was added at once to a solution of 4 $(0.50 \mathrm{~g}, 0.90 \mathrm{mmol})$ in THF $(50 \mathrm{~mL})$. A solid precipitated immediately upon addition. The product was isolated by centrifugation, and washed twice with THF (15 mL) to afford $\mathbf{5}$ as an off-white solid. The solid was used directly in the substitution reactions with tosylated polyglycerols.

Synthesis of polyorganometallic polyglycerols 3: Compound 5 (1.12.0 equivalents per $\mathrm{DP}_{\mathrm{n}}$ ) was added at once to a solution of tosylated polyglycerol $(0.2-0.5 \mathrm{~g})$ in DMF $(20 \mathrm{~mL})$. The solution was heated at $80^{\circ} \mathrm{C}$ for $16 \mathrm{~h}$, followed by removal of all volatiles in vacuum. The brownish residue was redissolved in dichloromethane and washed twice with $\mathrm{NaOH}(1 \mathrm{M})$ and brine. The solution was dried over $\mathrm{MgSO}_{4}$, concentrated to $5 \mathrm{~mL}$, filtered over Celite, and dialyzed against neat dichloromethane
$(250 \mathrm{~mL})$ to afford a brownish solid. The product was then dissolved in THF and purified with preparative GPC by using THF as an eluent. A yellow fraction was first isolated which corresponded to compound $\mathbf{3}$ with $50 \%$ tosylated and $50 \%$ substituted with $\mathbf{5}(50 \%)$. The second fraction was discarded, since it corresponded to the free-platinum pincer complex 5.

Compound 3: $M_{\mathrm{n}}=10541 ;{ }^{1} \mathrm{H}$ NMR $\left(300 \mathrm{MHz}, \mathrm{CDCl}_{3}\right) \delta=2.41(3 \mathrm{H}$; $\mathrm{CH}_{3}$ tosylate), $3.19\left(12 \mathrm{H} ; \mathrm{NMe}_{2}\right.$ pincer $), 4.07\left(4 \mathrm{H} ; \mathrm{CH}_{2} \mathrm{~N}\right.$ pincer $), 5.4-3.0$ (m, PG), 7.32 (2 H; ArH tosylate), $7.56(2 \mathrm{H}$; ArH pincer $), 7.77 \mathrm{ppm}$ $\left(2 \mathrm{H}\right.$; ArH tosylate); ${ }^{13} \mathrm{C}\left\{{ }^{1} \mathrm{H}\right\}$ NMR $\left(75.4 \mathrm{MHz}, \mathrm{CDCl}_{3}\right) \delta=130.2,155.0$, $144.1,127.9,125.2,120.1,77.3,81-78,74-68,55.1,42.7 \mathrm{ppm} ;{ }^{159} \mathrm{Pt}\left\{{ }^{1} \mathrm{H}\right\}$ $\operatorname{NMR}\left(64.4 \mathrm{MHz}, \mathrm{CDCl}_{3}\right) \delta=-1914$; IR $(\mathrm{KBr}): v=1720(\mathrm{C}=\mathrm{O}), 1420$ $1330 \mathrm{~cm}^{-1}(\mathrm{~S}=\mathrm{O})$; UV/Vis $\left(\mathrm{CHCl}_{3}\right): \lambda_{\max }(\varepsilon)=262,324 \mathrm{~nm}$.

Conditions for double Michael addition: Ethyl cyanoacetate $(1.6 \mathrm{mmol})$ was added at once to a solution of methyl vinyl ketone $(4.8 \mathrm{mmol})$, Et $i \mathrm{Pr}_{2} \mathrm{~N} 0(16 \mathrm{mmol})$, and catalyst $(1 \mathrm{~mol} \%)$ based on its [Pt] content (12.5 sites for 3 ) in $5 \mathrm{~mL} \mathrm{CH}_{2} \mathrm{Cl}_{2}$. The mixture was stirred at room temperature, and $100 \mu \mathrm{L}$ aliquots for ${ }^{1} \mathrm{H}$ NMR spectroscopy analysis were taken in the course of the reaction. Full conversion of $\mathbf{3}$ was recovered from the product mixture by dialysis against neat dichloromethane $(250 \mathrm{~mL})$ for $48 \mathrm{~h}$. The catalytic materials and products were recovered separately in near quantitative yields ( $92 \%)$.

\section{Acknowledgment}

The Council for Chemical Sciences of The Netherlandś Organization for Scientific Research (CW-NWO), the Dutch Technology Foundation (STW), and the Netherlands Research School Combination Catalysis (NRSC-C) are acknowledged for supporting this work. S.-E. S. is a "Ramón y Cajal" program research associate (MCYT, Spain). He is also indebted to Alexander von Humboldt Foundation for support. H. F. and H. K. thank the Fonds der Chemischen Industrie (FCI) for support in the context of fellowships.

[1] For comprehensive reviews on dendrimers see: a) J. M. J. Fréchet, Science 1994, 263, 1710-1715; b) F. Zeng, S. C. Zimmerman, Chem. Rev. 1997, 97, 1681-1712; c) H. Frey, C. Lach, K. Lorenz, Adv. Mater. 1998, 10, 279-293; d) Dendrimers I-IV : Top. Curr. Chem. 1998, 197, 1-228; Top. Curr. Chem. 2000, 210, 1-308; Top. Curr Chem. 2001, 212, 1-194; Top. Curr. Chem. 2001, 217, 1-238; e) A. W. Bosman, H. M. Hanssen, E. W. Meijer, Chem. Rev. 1999, 99, 1665-1689; f) G. R. Newkome, C. N. Moorefield, F. Vögtle, Dendritic Molecules: Concepts, Syntheses, Perspectives, Wiley-VCH, Weinheim, 2001; g) S. M. Grayson, J. M. J. Fréchet, Chem. Rev. 2001, 101, 3819-3867; h) S. Hecht, J. M. J. Fréchet, Angew. Chem. 2001, 113, 76-94; Angew. Chem. Int. Ed. 2001, 40, 74-91.

[2] For specific reviews on metallodendrimers, see: a) E. C. Constable, Chem. Commun. 1997, 1073-1080; b) G. R. Newkome, E. He, C. N. Moorefield, Chem. Rev. 1999, 99, 1689-1746; c) M. A. Hearshaw, J. R. Moss, Chem. Commun. 1999, 1-8; c) H.-J. van Maanen, F. C. J. M. van Veggel, D. N. Reinhoudt, Top. Curr. Chem. 2001, 121-162; d) R. Kreiter, A. W. Kleij, R. J. M. Klein Gebbink, G. van Koten, Top. Curr. Chem. 2001, 217, 163-199; e) G. E. Oosterom, J. N. H. Reek, P. C. J. Kamer, P. W. N. M. van Leeuwen, Angew. Chem. 2001, 113, 1878-1901; Angew. Chem. Int. Ed. 2001, 40, 1828-1849; For reports on non-covalent incorporation of catalytically active metal complexes, see: f) R. van de Coevering, M. Kuil, R. J. M. Klein Gebbink, G. van Koten, Chem. Commun. 2002, 1636-1637; g) D. de Groot, B. F. M. de Waal, J. N. H. Reek, A. P. H. J. Schenning, P. C. J. Kamer, E. W. Meijer, P. W. N. M. Leeuwen, J. Am. Chem. Soc. 2001, 123, 8453-8458; h) M. Q. Slagt, S.-E. Stiriba, R. J. M. Klein Gebbink , H. Kautz, H. Frey, G. van Koten, Macromolecules 2002, 35, 5734-5737; for encapsulation of zerovalent metal particles, see: i) R. M. Crooks, M. Zhao, L. Sun, V. Chechik, L. K. Yeung, Acc. Chem. Res. 2001, 34, 181-190; and references therein.

[3] a) U. Kragl Industrial Enzymology, 2nd ed, (Eds.: T. Godfrey, S. West), Macmillan, Hampshire, 1996, p. 275-283; b) D. Astruc, F. 
Chardac, Chem. Rev. 2001, 101, 2991-3023; c) H. P. Dijkstra, G. P. M. van Klink, G. van Koten, Acc. Chem. Res. 2002, 35, 798810 ; d) R. van Heerbeek, P. C. J. Kamer, P. W. N. M. van Leeuwen, J. N. H. Reek, Chem. Rev. 2002, 102, 3717-3756.

[4] a) D. Astruc, C. R. Acad. Sci. 1996, 322, 757-766; b) M. Fischer, F. Vögtle, Angew. Chem. 1999, 111, 934-955; Angew. Chem. Int. Ed. 1999, 38, 884-905; c) S.-E. Stiriba, H. Frey, R. Haag, Angew. Chem. 2002, 114, 1385-1390; Angew. Chem. Int. Ed. 2002, 41, 1329-1334.

[5] a) P. J. Flory, J. Am. Chem. Soc. 1952, 74, 2718-2723; b) M. Jikei, M. Kakimoto, Prog. Polym. Sci. 2001, 26, 1233-1285; c) Y. H. Kim, J. Polym. Sci. Part A: Polym. Chem. 1998, 36, 1685-1698; d) B. I. Voit, J. Polym. Sci. Part A: Polym. Chem. 2000, 38, 2505; e) L. J. Markoski, J. S. Moore, I. Sendijarevic, A. J. McHugh, Macromolecules 2001, 34, 2695-2701.

[6] a) A. Sunder, R. Hanselmann, H. Frey, R. Mülhaupt, Macromolecules 1999, 32, 4240-4246; b) A. Sunder, H. Türk, R. Haag, H. Frey, Macromolecules 2000, 33, 7682-7692.

[7] a) A. Sunder, M. Krämer, R. Hanselmann, R. Mülhaupt, H. Frey, Angew. Chem. 1999, 111, 3758; Angew. Chem. Int. Ed. 1999, 38, $3552-3555$; b) R. Haag, J.-F. Stumbé, A. Sunder, H. Frey, A. Hebel, Macromolecules 2000, 33, 8158-8166; c) S.-E. Stiriba, H. Kautz, H. Frey, J. Am. Chem. Soc. 2002, 124, 9698-9699; for a general overview, see: d) A. Sunder, R. Mülhaupt, R. Haag, H. Frey, Adv. Mater. 2000, 12, 235-239.

[8] C. Schlenk, A. W. Kleij, H. Frey, G. van Koten, Angew. Chem. 2000, 112, 3587-3589; Angew. Chem. Int. Ed. 2000, 39, 3445-3447.

[9] For a recent review on NCN-pincer chemistry see: a) M. Albrecht, G. van Koten, Angew. Chem. 2001, 113, 3866-3898; Angew. Chem. Int. Ed. 2001, 40, 3750-3781, and references therein.

[10] M. Q. Slagt, R. J. M. Klein Gebbink, M. Lutz, A. L. Spek, G. van Koten, J. Chem. Soc. Dalton Trans. 2002, 2591-2592.

[11] Earlier accounts on the concept of direct observation of linear polymer molecules, that involve platinum, see: a) M. J. Richardson, Proc. R. Soc. London 1964, 279, 50; b) L. C. Sawyer, D. T. Grubb, Polymer Microscopy, Chapman and Hall: London, 1987; c) D. A.
Tomalia, A. M. Naylor, W. A. Goddard, Angew. Chem. 1990, 102, 119; Angew. Chem. Int. Ed. Engl. 1990, 29, 138.

[12] Reports on the visualization of dendrimers with TEM: a) G. R. Newkome, Z. Yao, G. R. Baker, V. K. Gupta, P. S. Russo, M. J. Saunders, J. Am. Chem. Soc. 1986, 108, 849-850; b) G. R. Newkome, G. R. Baker, M. J. Saunders, P. S. Russo, V. K. Gupta, Z. Yao, J. E. Miller, K. Bouillion, J. Chem. Soc. Chem. Commun. 1986, 752-753; c) D. A. Tomalia, H. Baker, J. Dewald, M. Hall, G. Kallos, S. Martin, J. Roeck, J. Ryder, P. Smith, Macromolecules 1986, 19, 2466-2468; d) G. R. Newkome, C. N. Moorefield, G. R. Backer, M. J. Saunders, S. H. Grossman, Angew. Chem. 1991, 103, 1207; Angew. Chem. Int. Ed. Engl. 1991, 30, 1178; e) S. D. Hudson, H.-T. Jung, V. Percec, W.-D. Cho, G. Johansson, G. Ungar, V. S. K. Balagurusamy, Science 1997, 278, 449-452; f) A. W. Bosman, A. P. H. J. Schenning, R. A. J. Janssen, E. W. Meijer, Chem. Ber. 1997, 130, 725-728; g) M. F. Ottaviani, P. Matteini, M. Brustolon, N. J. Turro, S. Jockusch, D. A. Tomalia, J. Phys. Chem. B. 1998, 102, 6029-6039; h) C. L. Jackson, H. D. Chanzy, F. P. Booy, B. J. Drake, D. A. Tomalia, B. J. Bauer, E. J. Amis, Macromolecules 1998, 31, 6259-6265; i) J. Ruiz, G. Lafuente, S. Marcen, C. Ornelas, S. Lazare, E. Cloutet, J.-C. Blais, D. Astruc, J. Am. Chem. Soc. 2003, 125, 7250-7257.

[13] Nomenclature: $\mathrm{P}\left(\mathrm{G}_{x} \operatorname{Tos}_{y}\right), x=\mathrm{DP}_{n}$ of polyglycerol, $y=$ degree of tosylate substitution per hydroxyl group.

[14] Although cationic NCN-pincer platinum complexes are not considered to be catalytically active in Lewis-acid-catalysed processes, they do accelerate selected examples to some extent; this in contrast to their highly active palladium analogues.

[15] EDX analysis of the samples failed due to the detection limits of this method, combined with the sensitivity of the material towards electron-induced damage.

[16] H. P. Dijkstra, C. A. Kruithof, N. Ronde, R. van de Coevering, D. J. Ramón, D. Vogt, G. P. M. van Klink, G. van Koten, J. Org. Chem. 2003, 68, 675-685.

Received: August 15, 2003 Revised: October 16, 2003 [F5454] 